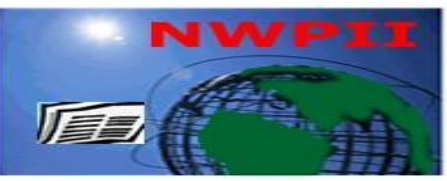

American Journal of Biomedical Sciences

ISSN: 1937-9080

nwpii.com/ajbms

\title{
Hydrothermal Synthesis of Hydroxyapatite from Calcium Sulfate Hemihydrate
}

\author{
Onur Rauf Bingöl, Caner Durucan*
}

Department of Metallurgical and Materials Engineering, Middle East Technical University, Ankara, TURKEY

"Corresponding author:

Caner Durucan, $\mathrm{PhD}$

Department of Metallurgical and Materials Engineering

Middle East Technical University

Ankara 06531

TURKEY

Phone : +90 (312) 210-5840

Fax : $\quad+90(312) 210-2518$

E-mail : cdurucan@metu.edu.tr

Received: 27 August 2010; $\mid$ Revised: 13 April 2011; | Accepted: 9 November 2011

\begin{abstract}
Commercial grade calcium sulfate hemihydrate $\left(\mathrm{CaSO}_{4} \cdot 0.5 \mathrm{H}_{2} \mathrm{O}\right.$, or plaster of paris, PoP) an economically feasible and abundant precursor has been used in $\left(\mathrm{Ca}_{10}\left(\mathrm{PO}_{4}\right)_{6}(\mathrm{OH})_{2}\right.$, HAp) synthesis. The synthesis was realized by reacting solid PoP precursor with $1 \mathrm{M}$ of $\left(\mathrm{NH}_{4}\right)_{2} \mathrm{HPO}_{4}$ aqueous solution, at ambient and mild hydrothermal conditions $\left(2 \pm 0.2 \mathrm{~atm}\right.$ and $\left.120^{\circ} \mathrm{C}\right)$. The effect of reaction temperature and pressure on PoP to HAp conversion efficiencies and reaction kinetics has been reported. The formation of HAp at a reaction temperature lower than $50{ }^{\circ} \mathrm{C}$ occurs at very limited extend; at $25^{\circ} \mathrm{C}$ HAp formation starts after 7 days. Extending the reaction time for low temperature reactions improves the HAp formation efficiency, meanwhile this also promotes precipitation of another calcium phosphate- $\mathrm{CaHPO}_{4} \cdot 2 \mathrm{H}_{2} \mathrm{O}$ together with HAp. At a reaction temperature of $90{ }^{\circ} \mathrm{C}$ HAp formation completes in 6 hours. Hydrothermal reaction conditions on the other hand significantly enhances reaction kinetics, where the transformation to HAp starts in $15 \mathrm{~min}$ and finalizes only in $90 \mathrm{~min}$. Hydrothermal reaction also hampers the formation of secondary phases, most likely originating from the impurities of low grade PoP precursor. The scanning electron microscopy analyses showed that HAp crystals are preferentially growing on the reactant PoP powders in a reticulated need-like morphology, suggesting a dissolution and reprecipitation mechanism for HAp formation. The findings showed that HAp synthesis can be accomplished by using a single and relatively cheap solid precursor under technological relevant hydrothermal conditions. Such synthesis routes can be practically expanded for making phase pure HAp powders in industrial scale.
\end{abstract}

Keywords: Calcium phosphates, calcium sulfate, hydroxyapatite, powder synthesis, hydrothermal synthesis. 


\section{Introduction}

Hydroxyapatite $\left(\mathrm{Ca}_{10}\left(\mathrm{PO}_{4}\right)_{6}(\mathrm{OH})_{2}\right.$, HAp $)$ is the main constituent of hard tissues. It has gained considerable attraction due to its excellent osteoconductive and osteointegration properties, allowing synthetic HAp to be used widely in clinical surgery and biomedical applications. In general, synthetic HAp powders are synthesized by precipitation [1-3], hydrolysis [4-6], sol-gel method [7], solid state reactions [8]. Some common problems for these synthesis techniques are, long reaction times, agglomeration, uncontrolled particle size and non-stoichiometric products. However, hydrothermal methods combine moderate temperatures with high pressures and they offer good control on morphology and chemical stoichiometry [9-13].

In this study calcium sulfate hemihydrate $\left(\mathrm{CaSO}_{4} \cdot 0.5 \mathrm{H}_{2} \mathrm{O}\right.$, or plaster of paris, $\left.\mathrm{PoP}\right)$ has been used in HAp synthesis via mild hydrothermal conditions. Previously, several studies have been employed to produce HAp from calcium sulfate sources using phosphate solutions [14-16]. Almost all of these studies, complete conversion to HAp was achieved; however, the reaction times can prolong from 4 hours up to 15 days, which makes them unfeasible for industrial scale bulk production.

The main objective of present study was to investigate the conversion kinetics of commercial grade PoP into HAp by treating with $1 \mathrm{M}$ of $\left(\mathrm{NH}_{4}\right)_{2} \mathrm{HPO}_{4}$ solution under hydrothermal conditions (2 atm, $120{ }^{\circ} \mathrm{C}$ ). The kinetics was compared to those achieved under ambient conditions (1 atm, $25{ }^{\circ} \mathrm{C}, 50{ }^{\circ} \mathrm{C}, 90{ }^{\circ} \mathrm{C}$ ). The analytical characterization performed by $\mathrm{x}$-ray diffraction (XRD) and scanning electron microscopy (SEM) analyses showed that under hydrothermal conditions, PoP was completely transformed into HAp in 90 min. As-synthesized hydrothermal reaction product was calcium deficient of moderate crystallinity. The thermal stability studies of the HAp product showed that the crystallinity can be further improved by calcination treatments lower than $600{ }^{\circ} \mathrm{C}$.

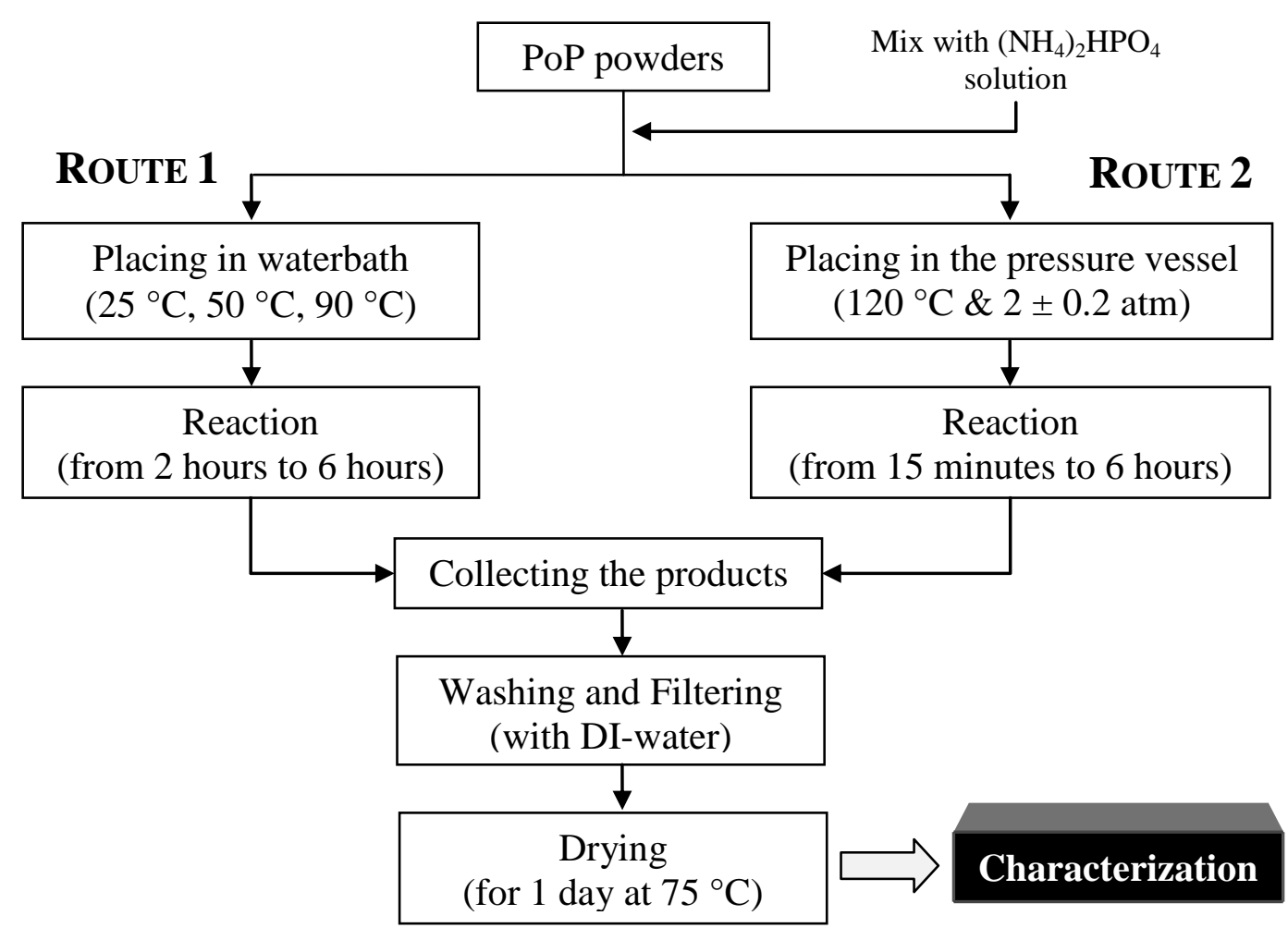

Figure 1. Experimental procedure for synthesis of HAp from PoP powders. 


\section{Materials}

Commercial grade plaster of paris $\left(\mathrm{CaSO}_{4} \cdot 0.15 \mathrm{H}_{2} \mathrm{O}\right.$, PoP, Knauf) are used for starting material to synthesize HAp powders. The average particle size of the PoP powders was around $55 \mu \mathrm{m}$. Di-ammonium hydrogen phosphate $\left(\left(\mathrm{NH}_{4}\right)_{2} \mathrm{HPO}_{4}, \quad 99.0 \%\right)$ obtained from Merck employed in preparing the aqueous reactant solution.
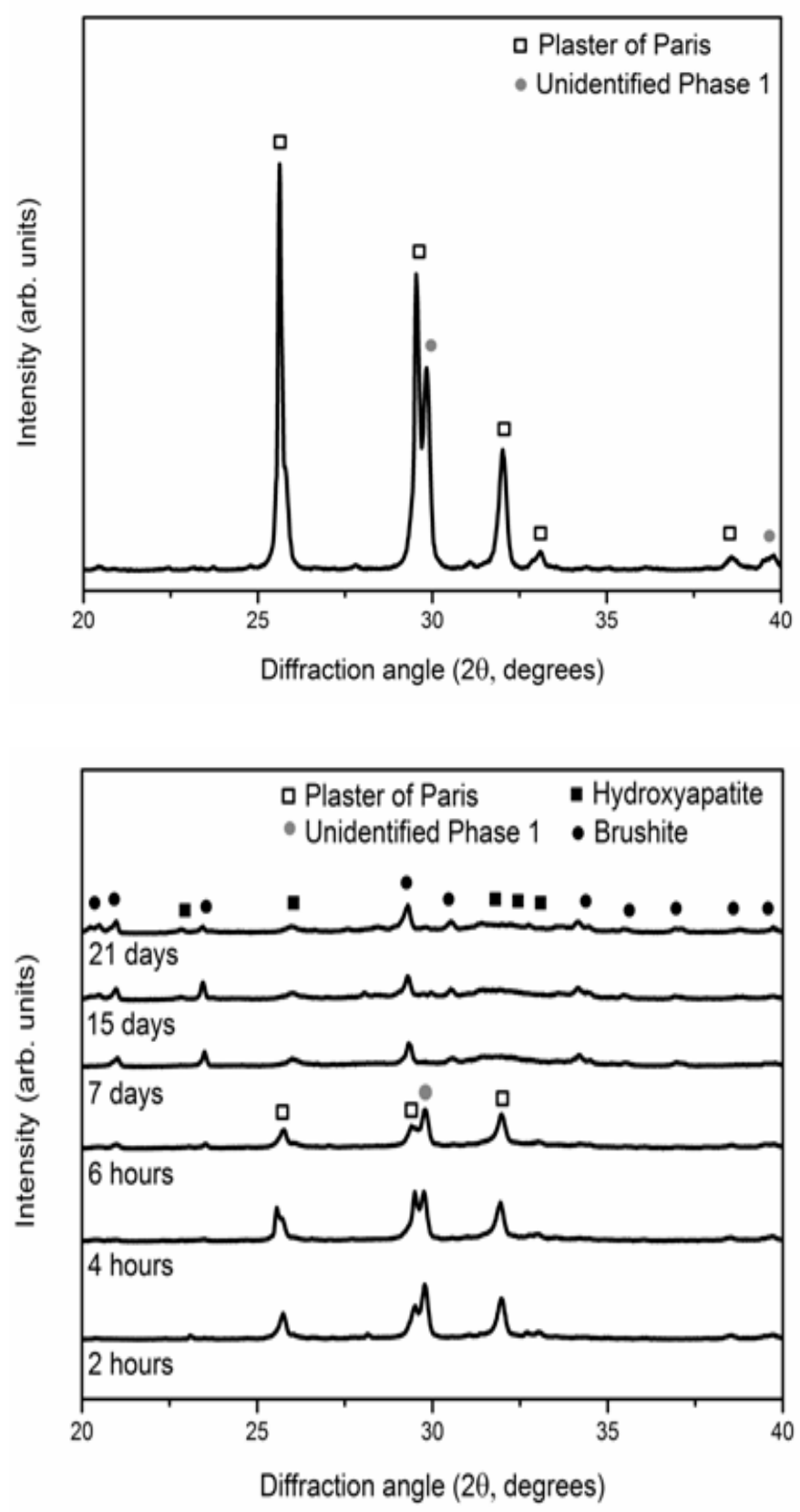

Figure 2. XRD diffractograms of unreacted PoP (top) and the product of reaction of PoP with $1 \mathrm{M}$
$\left(\mathrm{NH}_{4}\right)_{2} \mathrm{HPO}_{4}$ solution at $25{ }^{\circ} \mathrm{C}$ under ambient conditions. (bottom)

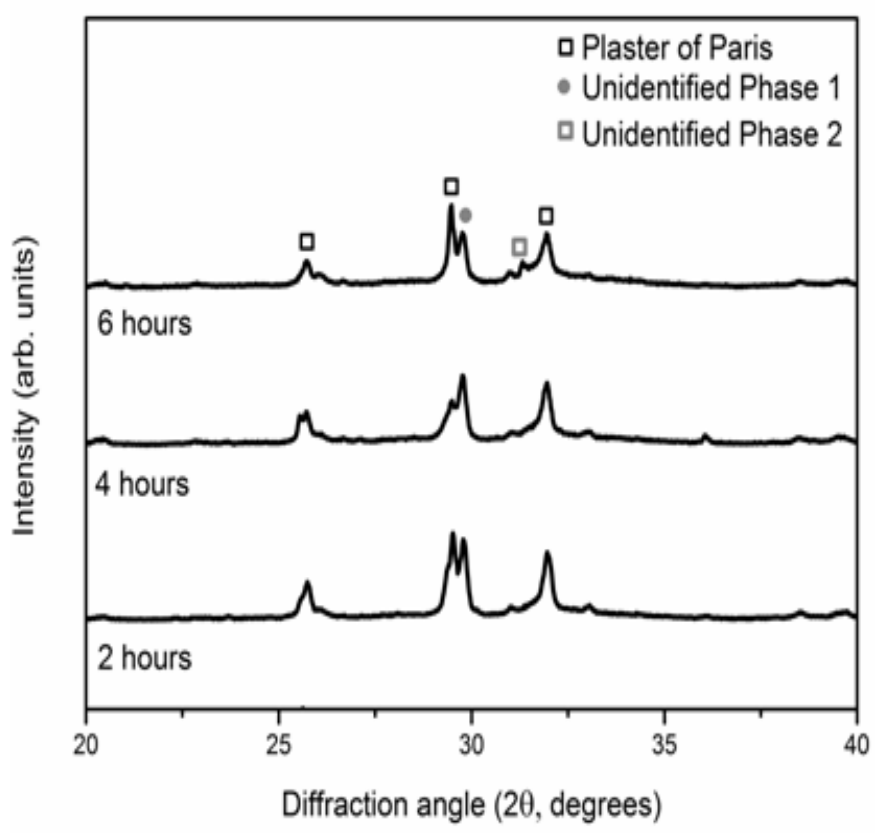

Figure 3. $\mathrm{XRD}$ diffractograms for the product of reaction of $\mathrm{PoP}$ with $1 \mathrm{M}\left(\mathrm{NH}_{4}\right)_{2} \mathrm{HPO}_{4}$ solution at $50^{\circ} \mathrm{C}$ under ambient conditions.

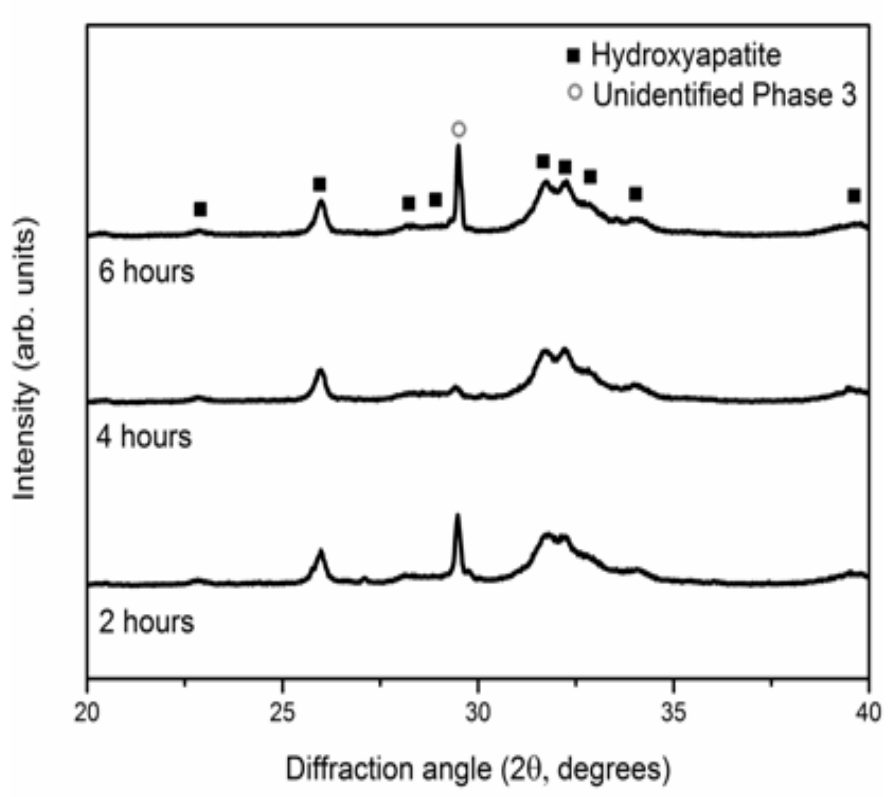

Figure 4. $\mathrm{XRD}$ diffractograms for the product of reaction of $\mathrm{PoP}$ with $1 \mathrm{M}\left(\mathrm{NH}_{4}\right)_{2} \mathrm{HPO}_{4}$ solution at 90 ${ }^{\circ} \mathrm{C}$ under ambient conditions. 


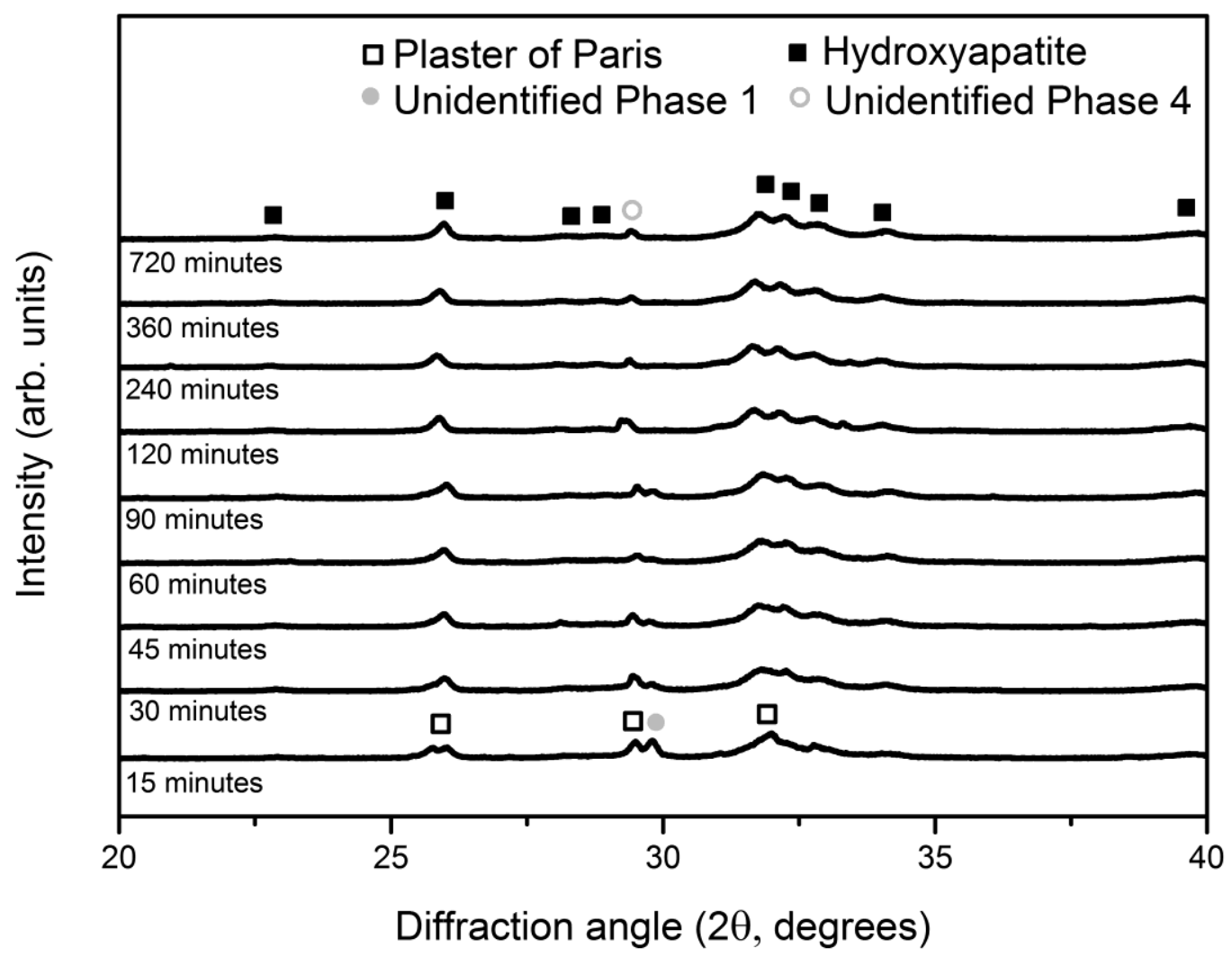

Figure 5. XRD diffractograms for the hydrothermal reaction product between PoP and $1 \mathrm{M}$ of $\left(\mathrm{NH}_{4}\right)_{2} \mathrm{HPO}_{4}$ solution.

\subsection{Synthesis of HAp}

HAp synthesis from PoP powders was achieved by two routes. The flowchart in Figure 1 shows the details for conversion of PoP powders to HAp. In Route-1, HAp was synthesized in powder form under ambient conditions at $25{ }^{\circ} \mathrm{C}$, $50{ }^{\circ} \mathrm{C}$ and $90{ }^{\circ} \mathrm{C}$ to investigate the effect of temperature on reaction kinetics. This reaction conversion was achieved according to the reaction below:

$10 \mathrm{CaSO}_{4} \cdot 0.15 \mathrm{H}_{2} \mathrm{O}+6\left(\mathrm{NH}_{4}\right)_{2} \mathrm{HPO}_{4} \rightarrow \mathrm{Ca}_{10}$ $\left(\mathrm{PO}_{4}\right)_{6}(\mathrm{OH})_{2}+6\left(\mathrm{NH}_{4}\right)_{2} \mathrm{SO}_{4}+4 \mathrm{H}_{2} \mathrm{SO}_{4}+1.4 \mathrm{H}_{2} \mathrm{O}$

Typically, $4 \mathrm{~g}$ of PoP was mixed with the 40 $\mathrm{mL} 1 \mathrm{M}$ of $\left(\mathrm{NH}_{4}\right)_{2} \mathrm{HPO}_{4}$ solution in a high density polyethylene (HDPE) container floated in the water bath at the reaction temperature. The reaction time varied from $15 \mathrm{~min}$ to $6 \mathrm{~h}$. For the reaction at $25 \mathrm{C}$, prolonged reaction times up to 21 days have been also performed. In Route-2, HAp was produced using a hydrothermal vessel to examine the effect of pressure on the conversion kinetics of PoP powders to HAp. Again $4 \mathrm{~g}$ of PoP powders was mixed with $40 \mathrm{~mL}$ of $\left(\mathrm{NH}_{4}\right)_{2} \mathrm{HPO}_{4}$ solution in HDPE bottle. Then, the bottle was put inside the pressure vessel operating at $2 \pm 0.2 \mathrm{~atm}$ and $120{ }^{\circ} \mathrm{C}$. The reaction time varied from $15 \mathrm{~min}$ to $6 \mathrm{~h}$. For both routes, at the end of reaction period, the solid products were washed with DIwater and filtered to eliminate any water soluble remains. After washing, the solid residue was put in open air drying oven operating at $75{ }^{\circ} \mathrm{C}$ for 1 day.

\subsection{Characterization}

X-ray diffraction (XRD) analyses were employed for the phase analysis of the starting PoP powder and the reaction products. The analyses were performed by a Rigaku Ultima 
D/MAX2200/PC X-Ray Diffractometer. CuKa radiation was used as an X-ray source at $40 \mathrm{kV}$. The scan speed was $2 \% \mathrm{~min}$. The samples were scanned over from $20^{\circ}$ to $40^{\circ}$ in $2 \theta$. The morphology of the PoP powder and the reaction products were examined by scanning electron microscopy (SEM) SEM analyses were performed by using a JEOL JSM-6400 Electron Microscope, equipped with a Noran System 6 Xray Microanalysis System and Semafore Digitizer. Samples were coated by Au-Pd alloy by an Anatech Hummle VII sputter coating device.

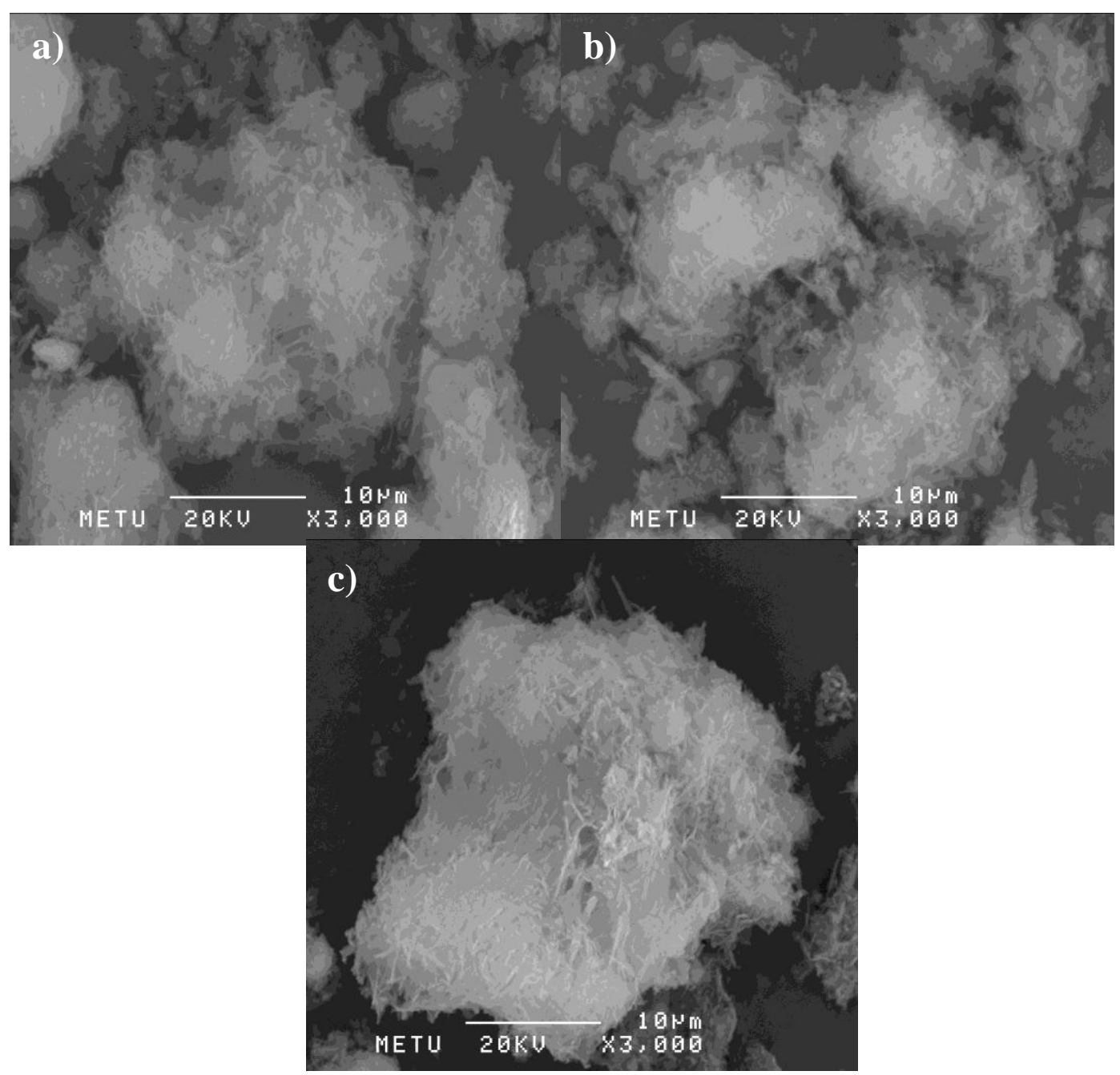

Figure 6. SEM micrographs of HAp products obtained under hydrothermal conditions after reaction with $1 \mathrm{M}$ $\left(\mathrm{NH}_{4}\right)_{2} \mathrm{HPO}_{4}$ solution for a) 2 hours, b) 4 hours and c) 6 hours.

\section{Results and Discussion}

Figure 2 shows the XRD diffractograms for unreacted PoP sample and the product obtained according to Route- 1 for the reaction of PoP with $1 \mathrm{M}\left(\mathrm{NH}_{4}\right)_{2} \mathrm{HPO}_{4}$ solution at $25{ }^{\circ} \mathrm{C}$ up to 21 days. Up to 6 hours no significant change occurs and the initial PoP powder stays as it is. Only some unidentified phase (labeled as Unidentified Phase 1) from the calcium sulfate source seems to be eliminated during initial periods of the reaction. After 7 days, the reactants mostly converted into brushite $\mathrm{CaHPO}_{4} \cdot 2 \mathrm{H}_{2} \mathrm{O}$ (JCPDS card no. 09077). In addition, small amounts of HAp (JCPDS card no. 09-432) was formed after 7 days, as revealed by broad peaks at round $2 \theta$ of $31^{\circ}-33^{\circ}$ 
which are characteristic to HAp. The XRD diffractograms in Figure 3 show the reaction products formed at $50{ }^{\circ} \mathrm{C}$ up to 6 hours. This set of data is comparable with the XRD patterns of the products formed at $25{ }^{\circ} \mathrm{C}$, and no HAp or some other calcium phosphate phase develops up to $6 \mathrm{~h}$. On the other hand, the reaction products of the 90 ${ }^{\circ} \mathrm{C}$-reaction was distinctly different as shown by the XRD diffractograms in Figure 4. The reaction seems to be more complete compared those reactions performed at $25{ }^{\circ} \mathrm{C}$ and $50{ }^{\circ} \mathrm{C}$, as the characteristic HAp diffraction peaks $\left(2 \theta \approx 31^{\circ}\right.$ $33^{\circ}$ ) can be more clearly observed even after $2 \mathrm{~h}$. As the reaction period was extended from $2 \mathrm{~h}$ to 6 $\mathrm{h}$, the HAp product becomes more crystalline and peaks becomes more distinct. The extra phases originating from $\mathrm{PoP}$ source have been also detected, however the detailed investigation and identification of these unknown has been considered trivial within general scope of the present work.

The XRD diffractograms in Figure 5 show the effect of pressure on conversion of PoP to HAp. Under hydrothermal conditions the conversion to HAp starts in $15 \mathrm{~min}$, which is considerably shorter than the conversion reaction at ambient conditions, and HAp is revealed by the broad characteristic peaks at $2 \theta \approx 31^{\circ}-33^{\circ}$. In $30 \mathrm{~min}$, more HAp is produced and some PoP remained unreacted. PoP was still present up to $90 \mathrm{~min}$ reaction; however, after 2 hours, the reaction seems to be complete to some extent. As reaction time increases, crystallinity of the HAp phase also enhances, but the crystallinity of HAp phase was still at moderate degree. Additionally, the extra phase (labeled as Unidentified Phase 1) converts into some other phase (labeled as Unidentified Phase 3) as reaction time increases. The intensity of the extra phase apparently reduces with time; however it is impossible to say that it can be eliminated at longer reaction times due to the uncertain behavior of these phases. The new unidentified extra phase also does not match with any standard JCPDS card.

The SEM micrographs in Figure 6 show the morphological details of the starting PoP powders together with HAp products obtained by hydrothermal reaction produced using $1 \mathrm{M}$ of $\left(\mathrm{NH}_{4}\right)_{2} \mathrm{HPO}_{4}$ solution. This figure shows the micrograph of HAp produced after $2 \mathrm{~h}, 4 \mathrm{~h}$ and $6 \mathrm{~h}$ reactions. According to this figure, the morphology of the particles has changed compared to their initial appearance shown in Figure 6a. The new form resembles the general prismatic structure of the $\alpha$-hemihydrate; however, the surface of these prismatic particles is covered with HAp crystals. It is impossible to predict the chemical composition of the interior side (core) of the particles; however the XRD data has shown that almost complete conversion to HAp has occurred in all cases. Newly formed HAp on the surface of the PoP particles has needle-like morphology with an approximate crystal size of 1 $\mu \mathrm{m}$ to $8 \mu \mathrm{m}$. The details of this morphological change can be more clearly seen by the SEM micrograph in Figure 7. It is possible to clearly observe the reticulated needle-like crystals of HAp with a primary particle size of $20-30 \mu \mathrm{m}$.

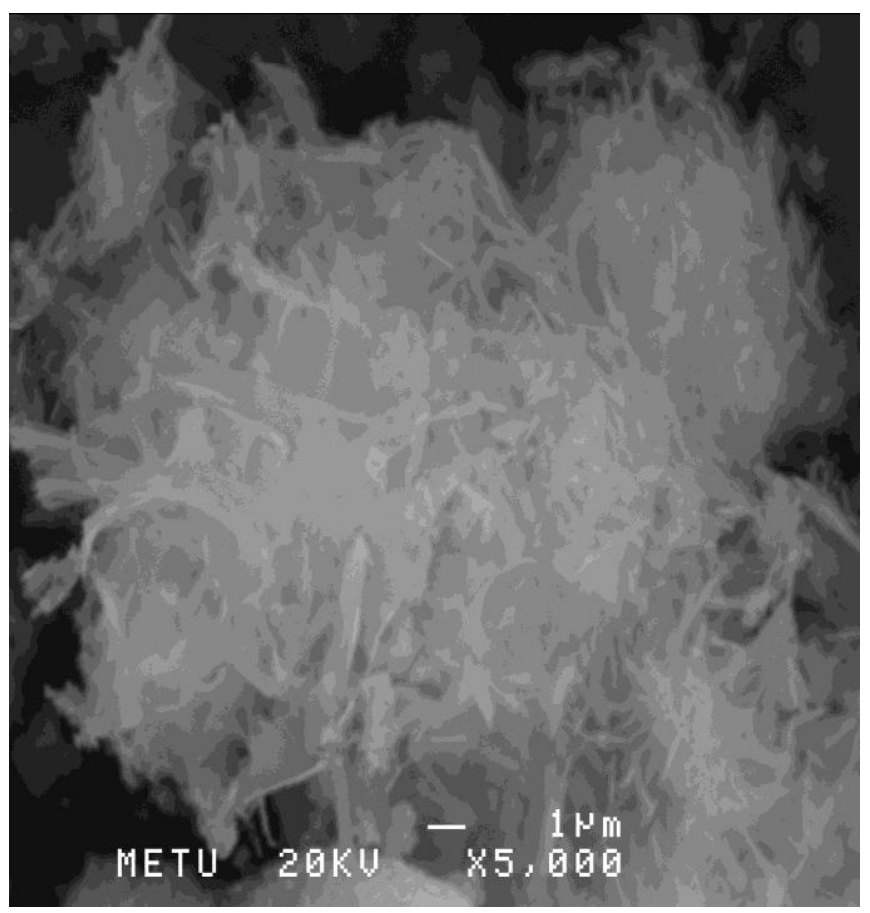

Figure 7. The detailed SEM micrograph of the HAp product obtained under hydrothermal conditions after reaction with $1 \mathrm{M}\left(\mathrm{NH}_{4}\right)_{2} \mathrm{HPO}_{4}$ solution for 4 hours. 


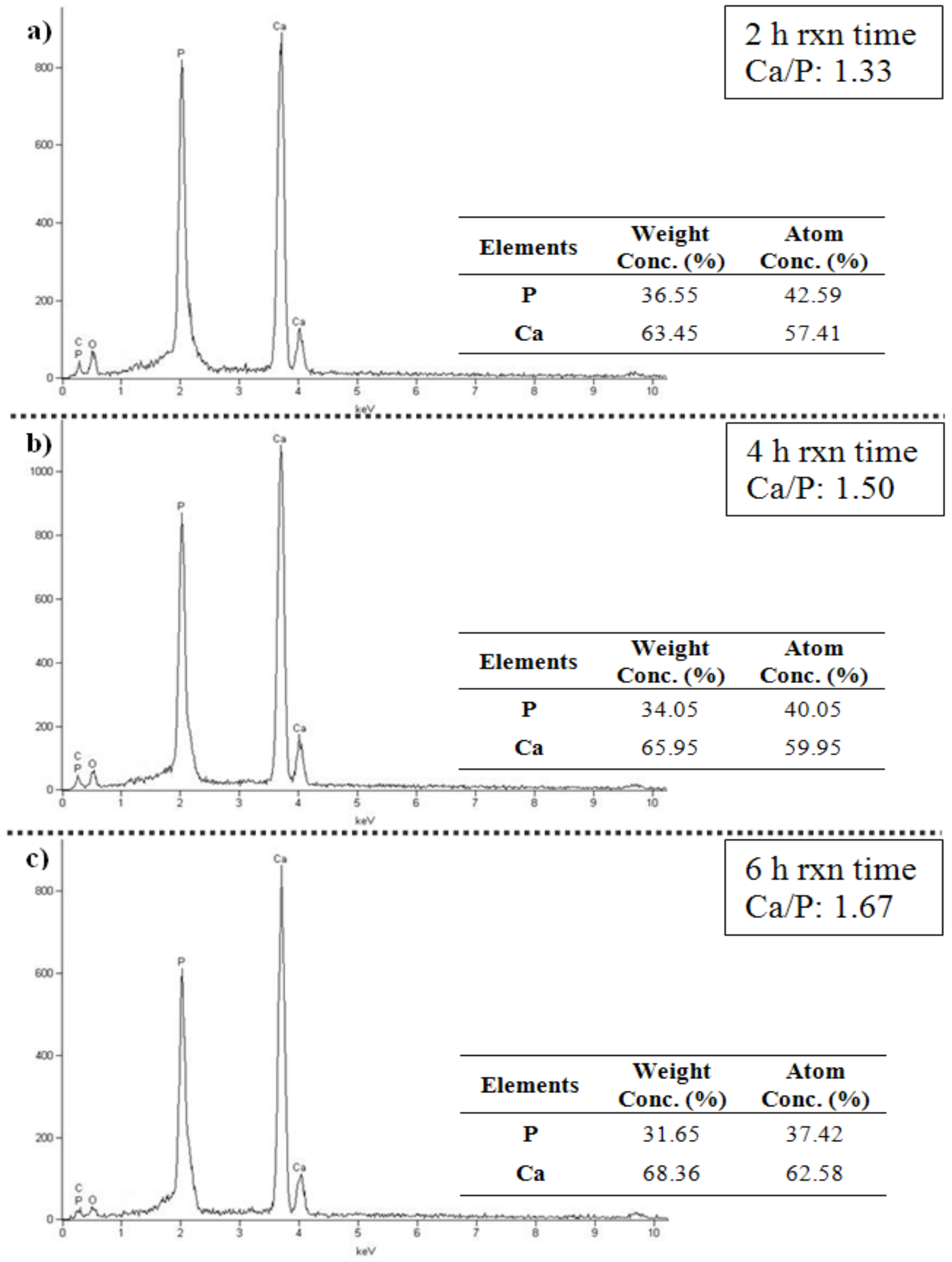

Figure 8. EDS spectra for HAp products obtained under hydrothermal conditions after reaction with $1 \mathrm{M}\left(\mathrm{NH}_{4}\right)_{2} \mathrm{HPO}_{4}$ solution for a) 2 hours, b) 4 hours and c) 6 hours. 


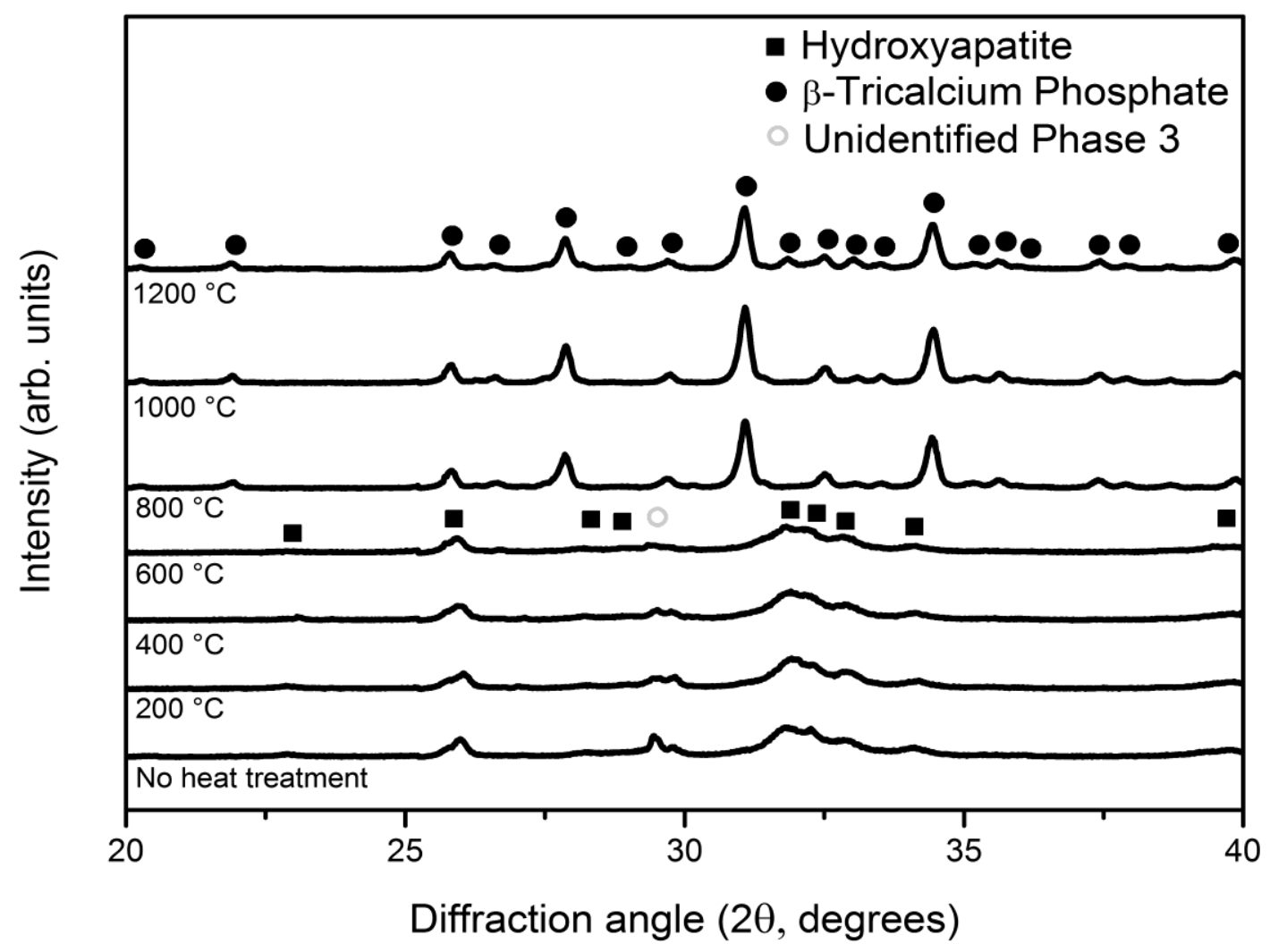

Figure 9. XRD diffractograms HAp product obtained under hydrothermal conditions after reaction with $1 \mathrm{M}$ $\left(\mathrm{NH}_{4}\right)_{2} \mathrm{HPO}_{4}$ solution for 30 minutes after heat treatment at different temperatures.

Additionally, the EDS spectra of the produced HAp powders shown in Figure 8 give some insights about the chemical nature of the reaction products obtained by hydrothermal conditions. According to the EDS spectra, $\mathrm{Ca} / \mathrm{P}$ ratio increases from 1.33 to 1.67 while the reaction time increases from $2 \mathrm{~h}$ to $6 \mathrm{~h}$. Even though, exact chemical composition analyses based solely on EDS data are questionable, these data, at least, show qualitatively that the reaction products forming in early stages are calcium-deficient. However, after prolonged and efficient reaction with $\left(\mathrm{NH}_{4}\right)_{2} \mathrm{HPO}_{4}$ solution, stoichiometric $\mathrm{Ca}_{10}\left(\mathrm{PO}_{4}\right)_{6}\left(\mathrm{OH}_{2}\right)$ with $\mathrm{Ca} / \mathrm{P}$ ratio of 1.67 can be produced with the hydrothermal reactions.

In order to identify the exact chemical identity of the HAp product, HAp powders, synthesized for $30 \mathrm{~min}$ under hydrothermal conditions, were heat treated from $200{ }^{\circ} \mathrm{C}$ to $1200{ }^{\circ} \mathrm{C}$ for $2 \mathrm{~h}$ and thermal stability of HAp powders is experimented. After the heat treatment operation, the samples were air cooled to room temperature $\left(25^{\circ} \mathrm{C}\right)$ and the resultant chemical phases were identified by XRD analyses. The phase changes upon heating of HAp can be related to the chemistry and stoichiometry of the HAp, i.e $\mathrm{Ca} / \mathrm{P}$ atomic ratio, with the help of the thermodynamic data provided by $\mathrm{CaO}-\mathrm{P}_{2} \mathrm{O}_{5}$ phase diagram [17].

The XRD diffractograms in Figure 9 show the phase changes for the HAp products obtained by 30-min upon heating up to $1200{ }^{\circ} \mathrm{C}$.The HAp product was found to be stable up to $600{ }^{\circ} \mathrm{C}$. Beyond $800{ }^{\circ} \mathrm{C}$ HAp converts into $\beta$-tricalcium phosphate $(\beta-\mathrm{TCP})$. While the heat treatment temperature increases, the crystallinity of the $\beta$ TCP phase increases. Additionally, the extra phase (labeled as Unidentified Phase 4) seems to be eliminated after the heat treatment operation at $800{ }^{\circ} \mathrm{C}$. The formation of $\beta$-TCP shows that the products have $\mathrm{Ca} / \mathrm{P}$ ratio between 1.50 and 1.67 which means the products are calcium deficient. 
HAp with exact stoichiometric $\mathrm{Ca} / \mathrm{P}$ ratio of 1.67 should be stable up to $1550{ }^{\circ} \mathrm{C}$ which incongruently melts at this temperature [17]. This finding correlate with EDS data, again revealing a $\mathrm{Ca} / \mathrm{P}$ ratio smaller than 1.67 for the HAp products forming in the early stages of hydrothermal reaction. In fact this is quite rational, as excess amount of phosphate reactant was in all experiments. This was done in order to achieve complete wetting of the PoP powders. Therefore, the resulting HAp was found to be Ca-deficient as suggested earlier by EDS analyses and proven by the qualitative evaluations performed by thermal stability studies.

\section{Conclusions}

PoP can be converted to HAp by reacting with aqueous phosphate solution both in ambient and mild hydrothermal conditions. However, hydrothermal condition offers several advantages both in terms of reaction kinetics and also in regard to the crystal nature and purity of the reaction product. At ambient conditions HAp formation completes in longer than 21 days and at around $6 \mathrm{~h}$, at $25^{\circ} \mathrm{C}$ and $90^{\circ} \mathrm{C}$, respectively. At hydrothermal conditions achieved in the present study, i.e. at $2 \pm 0.2$ atm and $120{ }^{\circ} \mathrm{C}$, this only takes about $90 \mathrm{~min}$. Besides the need for prolonged reaction times another problem associated with ambient reaction conditions is the formation of additional calcium phosphates with HAp product.

\section{Acknowledgment}

The financial support for this study was partially provided by METU-BAP program.

\section{References}

1. Liu, C., et al., Kinetics of hydroxyapatite precipitation at $\mathrm{pH} 10$ to 11 . Biomaterials, 2000. 22(4): p. 301-306. DOI: 10.1016/S01429612(00)00166-6

2. Koutsopoulos, S., Synthesis and characterization of hydroxyapatite crystals: A review study on the analytical methods.
Journal of Biomedical Materials Research, 2002. 62(4): p. 600-612. DOI: 10.1002/jbm. 10280

3. Mobasherpoura, I., et al., Synthesis of nanocrystalline hydroxyapatite by using precipitation method. Journal of Alloys and Compounds, 2007. 430(1-2): p. 330-333. DOI: 10.1016/j.jallcom.2006.05.018

4. Yoon, S.Y., et al., Synthesis of hydroxyapatite whiskers by hydrolysis of $\alpha$-tricalcium phosphate using microwave heating. Materials Chemistry and Physics, 2005. 91(1): p. 48-53. DOI: 10.1016/i.matchemphys.2004.10.049

5. Sinitsyna, O.V., et al., Synthesis of hydroxyapatite by hydrolysis of $\alpha-\mathrm{Ca}_{3}\left(\mathrm{PO}_{4}\right)_{2}$. Russian Chemical Bulletin, 2005. 54(1): p. 7986. DOI: $10.1007 / \mathrm{s} 11172-005-0220-9$

6. Arellano-Jiméneza, M.J., R. García-Garcíaa, and J. Reyes-Gasga, Synthesis and hydrolysis of octacalcium phosphate and its characterization by electron microscopy and X-ray diffraction. Journal of Physics and Chemistry of Solids, 2009. 70(2): p. 390-395. DOI: 10.1016/j.jpcs.2008.11.001

7. Anee Kuriakosea, T., et al., Synthesis of stoichiometric nano crystalline hydroxyapatite by ethanol-based sol-gel technique at low temperature. Journal of Crystal Growth, 2004. 263(1-4): p. 517-523. DOI: 10.1016/j.jcrysgro. 2003.11.057

8. Ramachandra Rao, R., H.N. Roopa, and T.S. Kannan, Solid state synthesis and thermal stability of HAP and HAP - $\beta$-TCP composite ceramic powders. Journal of Materials Science: Materials in Medicine, 1997. 8(8): p. 511-518. DOI: 10.1023/A:1018586412270

9. Yoshimura, M. and H. Suda, Hydrothermal Processing of Hydroxyapatite: Past, Present, and Future, in Hydroxyapatite nd Related Materials, P.W. Brown and B. Constantz, Editors. 1994, CRC Press: Boca Raton, FL.

10. Earl, J.S., D.J. Wood, and S.J. Milne, Hydrothermal synthesis of hydroxyapatite. Journal of Physics: Conference Series, 2006. 26(26): p. 268-271. DOI: 10.1088/17426596/26/1/064

11. Wang, Y., et al., Hydrothermal synthesis of hydroxyapatite nanopowders using cationic surfactant as a template. Materials Letters, 
2006. 60(12): p. 1484-1487. DOI: 10.1016/ j.matlet.2005.11.053

12. Fujishiro, Y., et al., Preparation of needle-like hydroxyapatite by homogeneous precipitation under hydrothermal conditions. Journal of Chemical Technology \& Biotechnology, 1993. 57(4): p. 349-353. DOI: 10.1002/jctb. 280570409

13. Roy, D.M. and S.K. Linnehan, Hydroxyapatite formed from coral skeletal carbonate by hydrothermal exchange. Nature, 1974. 247: p. 220-222. DOI: $10.1038 / 247220 \mathrm{a} 0$

14. Furuta, S., H. Katsuki, and S. Komarneni, Porous hydroxyapatite monoliths from gypsum waste. Journal of Materials Chemistry, 1998. 8(12): p. 2803-2806. DOI: 10.1039/A806659K

15. Lowmunkong, R., et al., Transformation of 3DP gypsum model to HA by treating in ammonium phosphate solution. Journal of Biomedical Materials Research Part B: Applied Biomaterials, 2006. 80(2): p. 386-393. DOI: $10.1002 / \mathrm{jbm} . b .30609$

16. Lowmunkong, R., et al., Fabrication of freeform bone-filling calcium phosphate ceramics by gypsum 3D printing method. Journal of Biomedical Materials Research Part B: Applied Biomaterials, 2008. 90B(2): p. 531-539. DOI: $10.1002 / \mathrm{jbm} . b .31314$

17. Kreidler, E.R. and F.A. Hummel, Phase relationships in the system SrO-P2O5 and the influence of water vapor on the formation of $\mathrm{Sr}_{4} \mathrm{P}_{2} \mathrm{O}_{9}$. Inorganic Chemistry, 1967. 6(5): $\mathrm{p}$. 884-891. DOI: $10.1021 / \mathrm{ic} 50051 \mathrm{a} 007$ 